\title{
Adherence of Granite Plates by Mortar Adhesion: Influence of Temperature
}

\author{
Rogério P. Ribeiro, Antenor B. Paraguassú, and Sérgio T. F. Moreiras
}

\begin{abstract}
The objective of this work was to study the effect of temperature variation on the adherence of granite plates fixed with adhesive mortars on external flooring and exterior cladding. The rock selected was a commercially well accepted syenogranite, known as Vermelho Capao Bonito, which has excellent technological qualities and high aesthetic value. Tensile bond strength and pullout tests were performed according to the techniques proposed for ceramic materials, in view of the lack of standards for dimension stones. The test specimens were set on standard substrates with two types of mortars, one commercially manufactured by a leader company and the other developed in laboratory. After normal curing conditions ( 28 days at $23^{\circ} \mathrm{C}$ and relative humidity of $65 \%$ ), the adhesion tests were performed at the following temperatures: $23^{\circ} \mathrm{C}, 30^{\circ} \mathrm{C}, 40^{\circ} \mathrm{C}, 50^{\circ} \mathrm{C}$ and $60^{\circ} \mathrm{C}$. With increasing temperature the results indicated a decrease in adhesion values of $48 \%$ to $42 \%$, from 2.04 to $1.13 \mathrm{MPa}$ for the one developed in the laboratory and from 1.92 to $1.12 \mathrm{MPa}$ for the commercial mortar. The behavior of the microstructure on the standard substrate-mortar-rock interfaces were also investigated by optical microscopy, and no signs of reaction or penetration of mortars into the rock (anchoring) were observed. With regard to the adhesion values, temperature variation was an important factor to its decrease, offering important perspectives for new experiments with other types of granites, for studies of displacements and pathologies commonly observed in external cladding made with plates of these materials.
\end{abstract}

Index Terms-Granite, mortar, adhesion.

\section{INTRODUCTION}

Mortar materials are widely used in civil construction. These materials are used in masonry, in plaster, in standard under floor-slab and also in the laying and grouting of ceramic and stone coverings.

The role of mortars are directly associated to their functions or applications. The role of adhesive mortars for ceramic or stone tile laying is to "glue" the ceramic or stone tile to the substrate and need to absorb the natural deformations the wall/structure system is subject to. It should be noted that adhesive mortars must have the capacity to absorb deformations (flexibility), especially when applied to facades, and should also have good adhesion and workability (water retention, open time, slip resistance and initial adhesion).

There are few studies that address rock adherence with

Manuscript received May 13, 2014; revised July 31, 2014. This work was supported by the Brazilian Agency for Research and Development - CNPq.

R. P. Ribeiro and A. B. Paraguassú are with the Engineering Geotechnical Department, University of São Paulo, São Carlos, SP 13566-590 Brazil (e-mail: rogerpin@yahoo.com, nonus@sc.usp.br).

S. T. F. Moreiras is with the Technology Department, State University of Maringá, Umuarama, PR 87506-370 Brazil (e-mail: strajano@gmail.com). adhesive mortars. However, several studies on the physico-mechanical properties of adhesive mortars and their adhesive characteristics with ceramics are found in the literature [1]-[3]. The increasing use of rocks in floor covering and buildings, especially due to lower prices of stone materials, has substantially increased the use of adhesive mortars, thus requiring more detailed studies to qualify them given the wide-ranging types of rocks currently found in market.

These aspects reinforce the need to expand the already obtained theoretical and practical knowledge on studies about ceramic materials for dimension stones, in order to understand the causes behind displacements and pathologies commonly observed on external claddings made with plates from these materials subject to diuturnal temperature variations.

The main objective of this paper was to study the effect of temperature variation on the adherence of granite plates set with adhesive mortars on external flooring and external cladding, taking into consideration an earlier study [4] related to this theme.

\section{MATERials}

\section{A. Dimension Stone}

The "granites" are well accepted in world markets, especially Brazilian granite, due to the vast chromatic and textural variety. The aesthetic factor is often decisive in the choice, which is the result of symmetry between the minerals' colors, sizes, shapes and arrangements.

In the present work one commercial type of "granite" known as "Vermelho Capao Bonito" was chosen, as it has good technological qualities and is well accepted in the international and domestic markets. It has low porosity, similar to porcelanates.

This rock is classified as a red-colored syenogranite, presenting an isotropic structure and an inequigranular aspect (Fig. 1). The texture is typically hipidiomorphic with granulations varying between medium and coarse ( 2 to $35 \mathrm{~mm}$ ) and a grain size distribution of 5 to $10 \mathrm{~mm}$. The mineral contacts are concave-convex and frequently impenetrable, resulting in an excellent mineral imbrication.

The essential minerals are quartz $(34.5 \%)$, microcline $(40.5 \%)$, oligoclase $(15.5 \%)$ and biotite $(6.0 \%)$; while accessory (1.5\%) opaque, apatite, sphene and zircon were observed together with the secondary minerals fluorite and hydrothermically altered $(<2.0 \%)$ sericite, muscovite, epidote, clorite, carbonate and clay minerals. The observed microcrack intensity (preferentially intergranular) was low 
and occurred generally in the quartz crystals.

Quartz was observed to occur preferentially as anhedral grain aggregates with an average dimension between 3 and $4 \mathrm{~mm}$ but as large as $10 \mathrm{~mm}$. They were commonly irregular, elongated and lenticulated in form giving the appearance of an interwoven rock matrix involving the microcline and plagioclastic crystals. Interpenetrating contacts with microcline crystals were observed and a clear inter-grain microcracking.

Microcline crystals up to $35 \mathrm{~mm}$ were present, giving the red coloration to the rock. The contours were clearly irregular, resulting in an excellent imbrication of the mineral. The plagioclase had average dimensions of 3 to $4 \mathrm{~mm}$ but occasionally reached $10 \mathrm{~mm}$. Saussuritizion was not prominent.

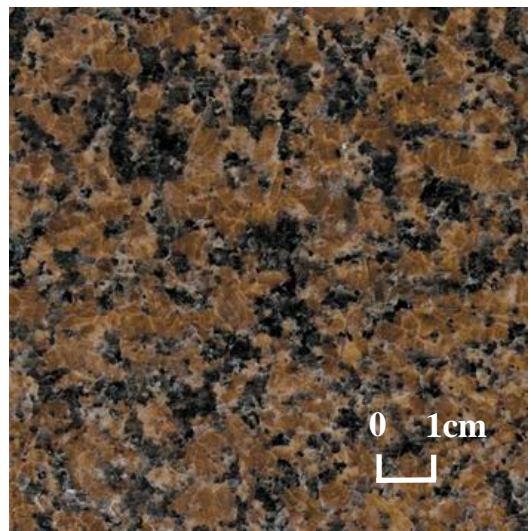

Fig. 1. Macroscopic aspect of a "Vermelho Capao Bonito" sienogranite tile.

\section{B. Mortars and Standard Substrate}

The mortar pastes or adhesive mortars, unlike the conventional ones, are applied in thin layers, leveled with strings. Their rheological and mechanical properties depend on the application technique, environmental conditions during preparation and components, particularly its additives (polymers and active silica).

In studies of stone plate setting using mortar, although it is a widely used technique, there is scarce information, mainly regarding bonding mortars, lacking standards and specifications for a good application. Therefore we use the NBR 14081-4 [5] standard recommended for ceramic plates.

There are specific adhesive mortars for granite and marble in the market. In this study, the specific mortar grout for granite and marble that is marketed worldwide, here called "Commercial Mortar" was compared with other type, here called "Mortar 3"[6] based on a laboratory-prepared mortar for porcelanate [7]. The reason this was chosen is due to the fact that porcelanate and granite have one characteristic in common, very low porosity $(<3 \%)$, does not allow anchoring, and the adherence is related to chemical bonds and/or intermolecular forces. Tensile bond strength tests carried out with single feldspar crystals (microcline) and quartz, predominant minerals in granitic rocks, showed that the quartz adherence is of about $50 \%$ of that verified for the feldspar [8].

The standard substrate was prepared according to the guidelines of NBR 14081-2 standard [9], which specifies the use of Portland cement, sand and gravel, with a water-cement ratio of 0.45 to 0.50 , a minimum cement content of 400 $\mathrm{kg} / \mathrm{m} 3$ and mass proportions of materials of 1:2.6:1.3.

\section{EXPERIMENTAL PROGRAM}

\section{A. Preparation and Settlement of Stone Specimens}

The extraction of the stone test specimens $(3.0 \mathrm{~cm}$ diameter discs) was performed on the tiles using a diamond column drill. The discs have two parallel faces, one polished and the other with a roughness (grooves) resulting from the traditional gang saw process. The adhesion tests were performed in specimens adhered to the mortar by rough surface.

In order to study the effect of temperature variation on the adherence of granite plates fixed with adhesive mortars on external flooring and external cladding, adherence tests were performed at temperatures of $23^{\circ} \mathrm{C}, 30^{\circ} \mathrm{C}, 40^{\circ} \mathrm{C}, 50^{\circ} \mathrm{C}$ and $60^{\circ} \mathrm{C}$ controlled by thermocouples placed at the mortar/rock interfaces. For the sake of additional safety, after stabilization the samples were kept at their respective temperatures for an additional period of 60 minutes.

20 test specimens were placed on each standard substrate, 10 fixed with a commercial mortar and the others with M3 mortar (Fig. 2), totaling 100 specimens. The rock/mortar/standard substrate sets were kept under normal curing conditions for 28 days, as specified in the standard (temperature of $23{ }^{\circ} \mathrm{C}$ and relative humidity of $65 \%$ ).

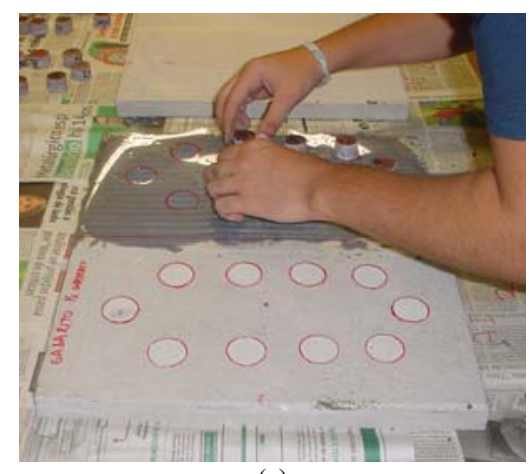

(a)

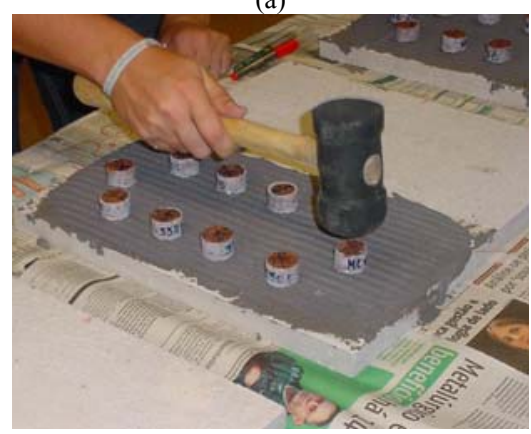

(b)

Fig. 2. (a) Positioning and (b) Settlement of the stone specimens in the Mortar 3 / Standard substrate set.

\section{B. Determination of Tensile Adhesion Strength}

This determination was performed according to NBR 14081-4 standard [5], which specifies a laboratory test method to determine the bond strength of adhesive mortar for ceramic materials, in view of the lack of standards for dimension stones. A test machine for direct pull tensile force 
and with suitable capacity and sensitivity for the tests was used (Fig. 3), where "C" is the metal cap connected to the equipment glued onto the test specimen by epoxy resin (disk) This machine is capable of applying the load to the pull-ahead plate at the rate of $(250 \pm 50) \mathrm{N} / \mathrm{s}$ through a suitable fitting that does not exert any bending force.

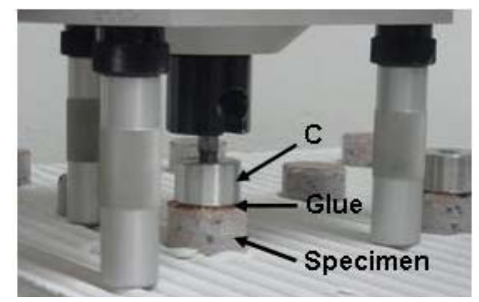

Fig. 3. Detail of the equipment used for the tensile bond strength test showing the connection detail between the metal cap glued to the stone and the equipment.

The statistical guidelines of the standard adopted refer to ceramic products (inert). Since dimension stones are natural materials with no technological control on its genesis and are consequently much more heterogeneous than a ceramic plate. Therefore, a percentage of the higher average variation, around $30 \%$, was adopted, which yielded more representative values for the tensile strength data analysis of the "Vermelho Capão Bonito" syenogranite.

The rock/mortar/standard substrate can undergo six types of rupture [5]: on the standard substrate; on the standard substrate/mortar interface; on the adhesive mortar layer; on the mortar/rock interface; the rock itself or due to the metal part adherence failure.

\section{Study of the Microstructure of Rock/Mortar Interface}

For the samples not subjected to pullout tests, vertical cuts with diamond disks were carefully made on the rock/mortar/standard substrate sets to obtain plates $40 \mathrm{~mm}$ long, $20 \mathrm{~mm}$ wide and $6 \mathrm{~mm}$ thick, which were used to prepare thin sections $(40 \mu \mathrm{m}$ thick), required for petro graphic analysis.

TABLE I: Descriptive Statistic PeRformed For the TensiLe Bond STRENGTH (TBS) VALUES

\begin{tabular}{lllllll}
\hline \multirow{2}{*}{$\mathrm{M}$} & \multirow{2}{*}{ Statistic } & 23 & 30 & 40 & 50 & 60 \\
\hline \multirow{3}{*}{$\mathrm{CM}$} & $\mathrm{N}$ & 5 & 7 & 6 & 6 & 5 \\
& Mean (MPa) & 1.92 & 1.34 & 1.13 & 1.12 & 1.12 \\
& $\mathrm{SD}$ & 0.52 & 0.31 & 0.19 & 0.18 & 0.06 \\
\hline \multirow{3}{*}{$\mathrm{M} 3$} & $\mathrm{~N}$ & 5 & 5 & 7 & 6 & 6 \\
& Mean (MPa) & 2.04 & 1.44 & 1.18 & 1.39 & 1.13 \\
& $\mathrm{SD}$ & 0.14 & 0.14 & 0.10 & 0.06 & 0.16 \\
\hline
\end{tabular}

mortar M; commercial mortar CM; mortar 3 M3; number of observations N; standard deviation SD.

\section{RESUlTS}

The results presented in Table 1 and Fig.4-5 show that in both mortars there was significant bonding strength decrease with increasing temperature, confirming the results from previous studies performed with ceramic materials [1]-[3]. A decreased of 48 to $42 \%$ in adhesion values with increasing temperature was observed, which ranged from 2.04 to 1.13 $\mathrm{MPa}$ for the one developed in the laboratory (Mortar M3) and 1.92 to $1.12 \mathrm{MPa}$ for the commercial mortar, which can cause cracks at the mortar-rock interface, allowing the penetration of fluids and resulting in displacements and pathologies.

In the pullout tests of the specimens fixed with the commercial mortar, $62 \%$ of ruptures occurred during the mortar/standard substrate contact. For the mortar developed in the laboratory (M3), $83 \%$ of ruptures occurred during the mortar-rock contact.

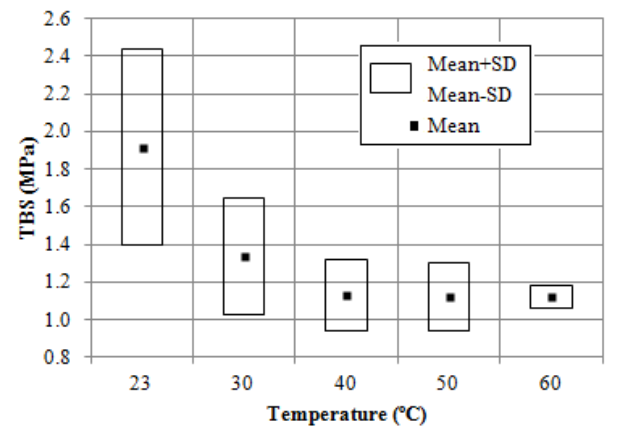

Fig. 4. Box plots of the tensile bond strength (TBS) results for commercial mortar CM.

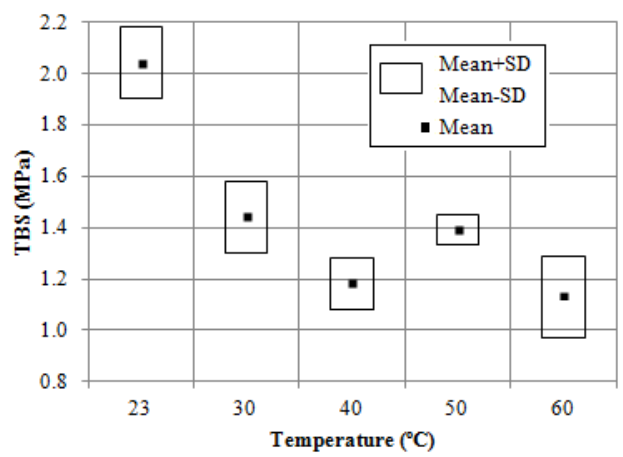

Fig. 5. Box plots of the tensile bond strength (TBS) results for mortar developed in the laboratory M3.

Regarding the microstructural behavior of the rock/mortar/standard substrate sets, the analysis of the thin sections with transmitted light showed tangible contacts of the stone plates with the mortar, with no edge reaction and no penetration of the mortar onto the stone (Fig. 6) in this level of observation. The anchoring only occurred on the standard substrate/mortar contact (Fig. 7).

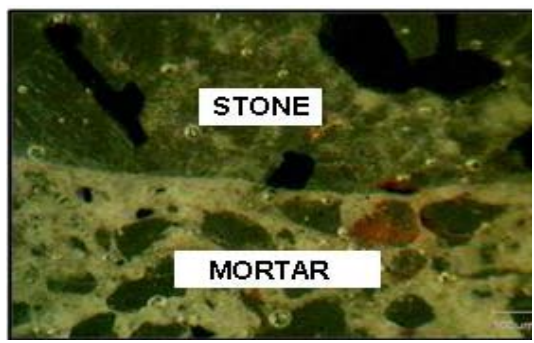

Fig. 6. Sharp stone/mortar contact with no edge reaction.

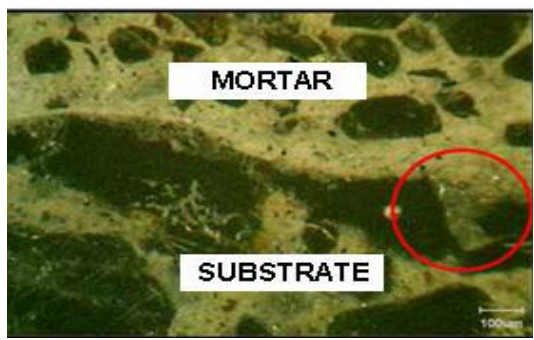

Fig. 7. Anchoring in the standard substrate/mortar interface. 


\section{CONCLUSiOnS}

The temperature variation has an important effect on reducing the bonding tensile strength of granite plates fixed with adhesive mortars. This is not a well known subject, has no standards, hence justifying research on the various types of commercial rocks used for outdoor cladding for floor coverings and building facades. Interestingly, in these low porosity stone materials $(<3 \%)$, adhesion is due to the electrochemical phenomena on the contact surface of the rocks, between the chemical charges of the main minerals and the mortar components.

\section{ACKNOWLEDGMENT}

The authors are pleased to acknowledge Paulo A. PrataVieira and Sergio A. Trevelin for their assistance during lab tests and Prof. Eduvaldo P. Sichieri for reviewing and discussion the manuscript.

\section{REFERENCES}

[1] F. Perez, "Adhesive mortars used to install ceramic tiles," M.S. thesis, Dept. Mat. Eng., University of São Paulo, São Carlos, Brazil, 2003.

[2] M. P. Bortoletto, "Evaluation of industrialized adhesive mortars, Type AC III, used as ceramic coating in building facades," M.S. thesis, Dept. Architecture, University of São Paulo, São Carlos, Brazil, 2004.

[3] A. M. V. D. O. Sá, "Adhesive mortar durability in ceramical cladding of façades," M.S. thesis, Dept. Civil Eng., University of Porto, Porto, Portugal, 2005

[4] L. Nogami, A. B. Paraguassú, J. E. Rodrigues, and R. P. Ribeiro, "Ceramic tests adaptations for rocks," in IV Congresso Brasileiro de Rochas Ornamentais, ISSN 2316-6215, 2012, pp. 511-521.

[5] Adhesive Mortars Industrialized for the Settlement of Ceramic Tiles, Part 4: Determination of the Bond Tensile Strength, ABNT Standart NBR 14081- 2012.
[6] L. Nogami, A. B. Paraguassú, J. E. Rodrigues, and R. P. Ribeiro, "Influence of the mineralogical and mortar components on the adherence of some granites," Key Eng Mat, vol. 548, pp. 267-274, 2013.

[7] A. E. F. D. S. Almeida and E. P. Sichieri, "Study of the influence of additions on the adhrence between polymer-modified mortars and porcelain stoneware tiles," Ceram, vol. 52, pp. 174-179, 2006.

[8] L. Nogami, A. B. Paraguassú, and J. E. Rodrigues, "Stone tiles cladding: adherence with bonding mortar," Rev. Bras. Geol. Eng. Amb, vol. 2, no. 1, pp. 135-142, 2012.

[9] Adhesive Mortars Industrialized for the Settlement of Ceramic Tiles, Part 2: Execution of the standard substrate and application of the fresh mortars for tests, ABNT Standart NBR 14081 - 2012.

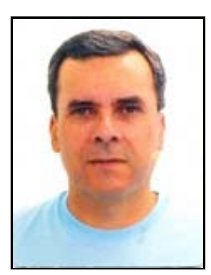

Rogério P. Ribeiro is a doctor in geotechnical engineering from University of São Paulo, he is a lecturer of Engineering Geology in Engineering School of São Carlos, University of São Paulo. His main subject of research is on characterization of rocks and sediments for using as construction materials. He has professional experience in mining exploration and dam projects.

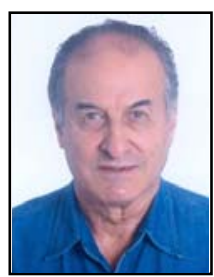

Antenor B. Paraguassú is a the doctor Geology, University of São Paulo in 1968. He is a full professor of engineering geology from Engineering School of São Carlos, University of São Paulo. His main subject of interest is focused on dimensional stones with emphasis in processing and slab affixing using adherent and non-adherent systems.

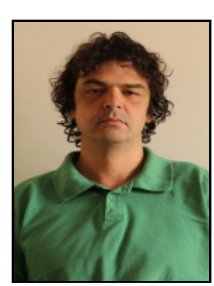

Sérgio T. F. Moreiras is a doctor in geotechnical engineering from University of São Paulo. He is a lecturer of geotechnical engineering at State University of Maringa, with professional experience in infrastructure design and construction. 